\title{
Mato Grosso
}

National Cancer Institute

\section{Source}

National Cancer Institute. Mato Grosso. NCI Thesaurus. Code C156323.

A state in the Central-West Region of Brazil. Its capital is Cuiaba. 